The two sets of seeds were thus in exactly similar conditions, except for the increased atmospheric pressure and the compression of the atmosphere in the one case as compared with the other. The following was the course of development:--By $9 \mathrm{a} . \mathrm{m}$. of the 9 th three of the seeds under the $2 \frac{1}{2}$ atmospheres of pressure had protruded their radicles, and this protrusion by i2 p.m. of the same day had become considerable, while as yet there was no indication of commencing germination in any of the seeds of the second set. By IO a.m. of the Ioth these latter had just begun to germinate, the radicles of the seeds under high pressure being at the time a fourth and a third of an inch long.

Henceforward, however, the rapidity of development was reversed. The seeds, under ordinary pressure, grew rapidly, and their cotyledons became of a deep yreen colour ; while the development of those under the high pressure became permanently arrested and the cotyledons of one that had entirely escaped from the seed-coats remained as etiolated as though they had been Jrown in absolute darkness.

They were allowed to remain untouched for eight days, when, as there was no change, the bottle was removed from the tube and simply allowed to stand inverted in the place it had formerly occupied. The two-out of the five-seeds which had hitherto remained unchanged now rapidly germinated, and grew into rigorous green young plants.

Does a greatly increased atmospheric pressure or a greatly compressed air prevent the development of chlorophyll, and while it stimulates germination does it prevent growth?

Liverpool, April 27

WILLIAM CARTER

[This is an interesting observation, and seems to suggest a new and comparatively unworked field of investigation-the effect of different amounts of atmospheric pressure on plant-life. With regard to the decomposition in the presence of chlorophyll and under the influence of sunlight, of carbon dioxide, it is remarked by Dehérain ("Cours de Chimie agricole," pp. 25, 26) that the conditions are analosous to those affecting the com bustion of phosphorus. This is not luminous in pure oxygen at ordinary pressure, but becomes so immediately the oxygen is diluted with nitrogen or hydrogen, and still more when the pressure is much diminished. Bousisingault has shown that leaves will not decompose pure $\mathrm{CO}_{2}$ at the ordinary atmo pheric pressure; but a small cherry-laurel leaf placed in the pure gas decomposed a cubic centimetre of it at a pressure of $17 \mathrm{~m}$. (Compt. rend., I865, t. 1x. p. 872.)]

\section{The Magnetic Survey of Missouri}

IT may interest some of your readers to know thint, although our State Legislature absolutely refused to do anything to aid in the Masnetic Survey of Missouri, refusing by a "crushing" vote even to authorise county officers to have a true meridian established, the work will still go on. A gentleman of St. Louis, whose name is withheld at his own request, bas assumed the entire expense, and we shall now begin a more minute examination of the Missouri, Grand, and Osage valleys. We shall hereafter travel by wagon, and shall do the work where it is most needed in order to disclose the real directions of the isogonic lines.

F. F. NIPHER

\section{An Optical Illusion}

THE illusion described by Mr. Wilson and commented on in an editorial note is anything but a novel one. An apparatus for the experiment was purchased by the Birmingham and Midland Institute, along with a quantity of optical apparatus, from $\mathrm{Mr}$. Robert Addams, in, I think, 1857. Within the last few years I have noticed that the experiment is described and explained in Priestley's "Light and Vision." I am writing from home, or would give the exact reference.

C. J. WOODWARD

Cambridge, May 23

I sHould like to know whether the following is a general experience, or only a peculiarity of my own vision?

If I stand with a source of li sht-a lamp or a window-at one side of my head, so that the light falls strongly on one eye only, and look, successively or simultaneously, at the images of a piece of white paper as seen by my two eyes, the image seen by the eye next the light is greenish white, and that seen by the eye farthest from it is light buff

If instead of white paper I use the gilt edges of a book, the image seen by the eye next the light is of a beautiful golden green; the other is of a brassy yellow, almost orange.

This phenomenon dues not appear to depend on any effect of dazzling, for the experiment succeeds perfectly with very moderate degrees of illumination. JOSEPH JOHN MURPHY

Old Forge, Dunmurry, co. Antrim, May 23

\section{The Speaking Tube Anticipated?}

HAs the following appeared anywhere in this connection as yet, or not? If not, please allow it to appear in NATURE with this qualification only, that the italics are mine.

Describing the "speaking trumpets or pipes which ran, we are told, along the whole length of the Wall," Bruce says ("The Roman Wall," by the Rev. John Collingwood Bruce, p. 76), that Drayton long ago sang of them as follows in his "Polyolbion":-

$$
\begin{aligned}
& \text { "Townes stood upon my length, where garrisons were laid } \\
& \text { Their limits to defend : and for my greater aid } \\
& \text { With turrets I was built, where sentinels plac'd } \\
& \text { To watch upon the Pict: to me my makers grac'd } \\
& \text { With hollow pipes of brasse, along me still they went, } \\
& \text { By zohich they in one fort still to another sent } \\
& \text { By speaking in the sume to tell them what to doe, } \\
& \text { And soe from sea to sea could I be whispered through." }
\end{aligned}
$$

Ashton-under-Lyme, May 17

W. CURRAN

T. C. Shenstone.-A case of Phyllody of the calyx. "Ranunculacece particularly liable to this change" (Master's "Teratology," p. 246 ; recorded in Anemone nemorosa, ibid. p. 252).

\section{ORIGIN OF THE ENGLISH MILE ${ }^{1}$}

$\mathrm{T} \mathrm{T}$ is known that the mile of 1609 metres long passed among English geographers and navigators as being the length of the terrestrial arc of $\mathrm{I}^{\prime}$; in other words they made the degree equal to 60 of these miles. In reality it contains $69^{\circ} 5$; there is thus an error of about one-sixth. This error, if it existed long among our neighbours, which I do not know, must have caused many a shipwreck. It has had another very remarkable result; it nipped in the bud the discovery of the law of universal attraction. The first time that Newton's great idea presented itself to his mind the proof failed him, because he made use of the common English mile to calculate the radius of the earth. He renounced the idea for a long time, and only took the calculation up again when he learned the results of Picard's measurement of a degree in France. Whence comes this defective estimate? Certainly it does not proceed from any effective measurement, for the worst degree measurements, among those which have been really made, and not fictitious measurements, like that of Posidonius, are far from presenting errors of such magnitude. English geographers then must have committed some mistake in taking their mile from ancient documents. So long as navigation was limited to the waters of the Mediterranean, and to coasting along the western shores of Europe, it was scarcely necessary to trouble about the value of this element; but from the time that the discoveries of the Spaniards and Portuguese opened out a much vaster field, sailors were compelled to make some inquiry into the matter. I suppose that the English navigators applied to their geographers, and that these found nothing better to consult than Ptolemy, the great, the only authority in these matters. But Ptolemy himself refers to Eratosthenes; he says that he verified the measurements of the latter and found the same result, viz. 500 stadia for the terrestrial degree. I have thus been led to examine the measurement of Eratosthenes. According to the documents which historians have preserved, Eratosthenes measured the great arc of meridian which separates the parallels of Syené and Alexandria, and finally found 700 stadia to the degree. This is how he worked:- He observed at Alexandria, certainly by means of a gnomon, the zenith distance of the sun at $x$ Paper read at the Paris Academy of Sciences by M. Faye (Comptes rendits, xcii. No. $x 7$ ). 
midday in the summer equinox, and thus found $7^{\circ} 12^{\prime \prime}$. It is added that at Syené the bottom of the wells was fully lighted by the sun on that day, so that Eratosthenes concluded zero for the zenith distance of that body. I believe rather that the Greek astronomer caused an observation to be made at Syené with a gnomon, an instrument then very common in Egypt, and that that distance resulted from an effective observation, as well as in the case of Alexandria. We shall see that this conjecture is perfectly justified. We know that the observations made on the dark shadow of a gnomon bear a constant error equal to the semi-diameter of the sun, or, to speak more accurately, that they give the zenith distance of the upper edge of that body. The ancients do not seem to have remarked this; and in fact, as they deduced from their abservations only the obliquity of the ecliptic or the epoch of the solstice, it did not concern them, for by combining the observations of the summer with that of the winter solstice, the error in question disappeared from the difference. But it is exactly the same here, since we have not to do with absolute latitude, but with the difference of latitude of two places at which the centre of the sun is found at midday on the same side of the vertical. Thus the amplitude $7^{\circ} 12^{\prime}$ concluded by Eratosthenes is correct; it has moreover the advantage of not being sensiby affected by refraction.

Here is a first verification. On opening the Connaissance des Temps we find-

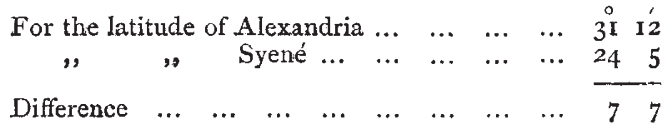

instead of $7^{\circ} 12^{\prime}$. The difference, whatever may be the cau'se, is very small.

Here is a second and more delicate verification. The latitude of the point in Alexandria, where Eratosthenes observed, could not differ much from that which we have given. By adopting that and $7^{\circ} 12^{\prime}$ for the zenith distance of the upper edge of the sun at the winter solstice we find $31^{\circ} 12^{\prime}-\left(7^{\circ} 12^{\prime}+16^{\prime}\right)=23^{\circ} 44^{\prime}$ for the obliquity of the ecliptic. Syené gives $24^{\circ} 5^{\prime}-16^{\prime}=23^{\circ} 49^{\prime}$. Is it possible that in the year 250 B.C. the obliquity of the ecliptic was from $23^{\circ} 44^{\prime}$ to $23^{\circ} 49^{\prime}$ ? From $175^{\circ}$ A.D. to 250 B.C. is 2000 years. At the rate of $48^{11}$ diminution per century the obliquity would be

$$
23^{\circ} 28^{\prime} \text { I } 8^{\prime \prime}+48^{\prime \prime} \times 20=23^{\circ} 44^{\prime} \text {. }
$$

The observation of Eratosthenes at Alexandria is then authentic, and moreover very precise. That of Syené presents an error of only $5^{\prime}$.

There remains the geodetic operation. Egypt was the only country of antiquity which rejoiced in a survey. The valley of the Nile was very populous at that epoch, as far as Syené, and no doubt the survey extended thus far. Eratosthenes must have had every facility for procuring the necessary documents. $\mathrm{He}$ must have taken into account the difference of longitude of $2^{\circ} 59^{\prime}$ which exists between the two cities, without having had to determine it directly. I regard, then, the distance of 5000 stadia, in round numbers, as being quite as accurate as the other parts of his operation, and as applying to the arc of meridian comprised between the parallels of the two cities.

We finally conclude from this 694.4 stadia for the degree. The Greek astronomer gave, in round numbers, 700 stadia. What was this stadium?

To reply to this question I calculate the arc of meridian from Alexandria to the parallel of Syené, with the actual element of the terrestrial ellipsoid. It is 797,760 metres. At the rate of 5000 stadia we find $159^{\circ} 55$ metres for the stadium. At the rate of 600 feet for the stadium, the foot adopted by Eratosthenes would be 0.266 metres. This was then the ancient Egyptian foot, which we now reckon at 0.27 metre; and in fact it was with this foot that the survey of Egypt must have been made. By this reckoning the 5000 stadia give--

$$
5000 \times 600 \times 027=810,000 \text { metres, }
$$

showing a difference of 12,240 metres, partly owing to that of the points of departure, partly to the error which we perhaps make in the length of the Egyptian foot in carrying it to $0^{\prime} 27$ metre. Thus the measurement made in Egypt, more than 2100 years ago, by an able Greek astronomer, is as good as authentic. All the existing causes of uncertainty do not alter it more than one-sixth. It is certainly not from this quarter that the error can come for which we seek.

Nor is it in the measurement of Ptolemy, for he tells us he went through the same operations and found the same results; only he gives 500 stadia to the degree instead of 700. This difference is evidently due to the fact that Ptolemy, who lived 400 years after Eratosthenes, under another domination, did not make use of the same foot. In fact he employed the stadium of 600 Phileterian feet, and as this foot is about 0.36 metre, while the ancient Egyptian foot was only 0.27 metre, he had to reduce the 700 stadia of his predecessor to $700 \times \frac{27}{36}$ $=525$, or 500 in round numbers.

These estimates are confirmed, finally, by the Arabian astronomers, who measured, in 827 A.D., an arc of $I^{\circ}$ in the plains of Mesopotamia. They found fifty-six miles, and concluded that they had thus verified the number of Ptolemy. The Arab mile being 2100 metres, the arc measured is found to be 117,600 metres, which corresponds to a stadium of 235 metres. This is very nearly the Phileterian stadium of 216 metres, except the error of the measurements seven times more sensible on so small an axis, and the uncertainty of our existing estimate of the Arabian mile in the time of the Kalif Almamoun.

To resume: the estimate of Ptolemy is only a sort of conversion of the excellent measurement of Eratosthenes in units of another epoch and of different length. It would thus lose a little of its first precision; but, such as we find it in Ptolemy, the English geographers were fully justified in taking it for the basis of a valuation of the arc of $\mathrm{I}^{\prime}$ and of offering it to the navigators of their country. Only, and it is here the mistake lies, they believed that the great Greek astronomer of Alexandria must have made use of the Greek foot. This is one and a half hundredths larger than the English foot. If the English geographers of the sixteenth century had strained this valuation ever so little, and had carried it to $\frac{5}{30}$ ths, they would have found 630 English feet for the stadium, which they believed to be 600 Greek feet, and these 630 feet or 2 Io yards, multiplied by 500 , would give them 105,000 yards for the degree, and exactly 1760 yards for the mile. The English mile, then, has evidently been deduced from the measure of Ptolemy; its error of one-sixth is solely due to the fact that the Greek foot has been confounded with the Phileterian foot.

\section{LAURENTIAN GNEISS CFF IRELAND}

I N I 863 Dr. T. Sterry Hunt pointed out the resemblance of some specimens of rocks and minerals from Donegal which he had examined to those of the Laurentian series of North America. These rocks and minerals have been described by Dr. Haughton and Mr. R. H. Scott, who have pointed out that the "typical Donegal granite" is really a metamorphic bedded rock, containing in some places bands of crystalline limestone or marble. Oatside the granite district are the newer series of schists, quartzites, and limestones, which occupy the whole of the Promontory of Innishowen, and were identified by the late Prof. Harkness with the Lower Silurian metamorphic series of the Highlands of Scotland. These two groups are shown on Griffith's Geological Map of Ireland, and it 